\title{
REGULACIÓN DE LA CADUCIDAD DEL PERMISO DE PESCA Y DE LA LICENCIA DE OPERACIÓN DE PLANTAS DE PROCESAMIENTO EN LA LEY GENERAL DE PESCA Y SU REGLAMENTO
}

\section{REGULATION OF THE EXPIRATION OF THE FISHING PERMIT AND OF THE OPERATING LICENSE OF PROCESSING PLANTS IN THE GENERAL FISHERIES LAW AND ITS REGULATIONS}

\author{
Nery Yanet Oblitas Sánchez \\ Abogada \\ Universidad Nacional Mayor de San Marcos \\ noblitass@gmail.com \\ Perú, Lima
}

\section{SUMARIO}

- Introducción.

- Regulación de la caducidad en la Ley General de Pesca y su Reglamento.

- Conclusiones.

\section{RESUMEN:}

El presente artículo tiene como finalidad dar a conocer la regulación de la caducidad en la Ley General de Pesca, Decreto Ley N $^{\circ} 25977$, y su Reglamento, aprobado por Decreto Supremo $\mathrm{N}^{\circ}$ 012-2001-PE, y en qué casos corresponde declararla, específicamente en lo que respecta al permiso de pesca y la licencia de operación de plantas de procesamiento.

En efecto se expone la forma en que se encuentra regulada la caducidad y las causales por las cuales la Administración procede a declararla, así como respecto a su naturaleza.

\begin{abstract}
:
The present paper is intended to make known the regulation of the expiration in the General Fishing Law, Decree Law No. 25977, and its Regulations, approved by Supreme Decree No. 012-2001-PE, and in which cases it is necessary to declare it, specifically with regard to the fishing permit and the operating license of processing plants.
\end{abstract}

In effect, the way in which the expiration is regulated and the reasons for which the
Administration proceeds to declare it, as well as its nature, is set forth.

\section{PALABRAS CLAVE}

Permiso de pesca; licencia de operación; caducidad.

\section{KEYWORDS}

Fishing permit, operation license; expiration.

\section{INTRODUCCIÓN}

De acuerdo a lo dispuesto en los artículos 66, 67 y 68 de la Constitución Política del Perú, los recursos naturales son patrimonio de la Nación y le corresponde al Estado peruano promover no solo uso sostenible, sino también la conservación de la diversidad biológica.

Asimismo, según el artículo 2 de la Ley General de Pesca, Decreto Ley N ${ }^{\circ} 25977$ :

Son patrimonio de la Nación los recursos hidrobiológicos contenidos en las aguas jurisdiccionales del Perú. En consecuencia, corresponde al Estado regular el manejo integral y la explotación racional de dichos recursos, considerando que la actividad pesquera es de interés nacional.

Las disposiciones que regulan la actividad pesquera se encuentran en principio en la Ley General de Pesca, su reglamento y en los reglamentos de ordenamiento pesquero para determinado recurso, entre otros. 
La actividad pesquera está comprendida por la actividad de investigación, la actividad extractiva y el procesamiento, conforme se desprende de la Ley General de Pesca.

La extracción se encuentra definida en dicha ley como la "fase de la actividad pesquera que tiene por objeto la captura de los recursos hidrobiológicos (...)" (artículo 19), mientras que la actividad de procesamiento como "la fase de la actividad pesquera destinada a utilizar recursos hidrobiológicos con la finalidad de obtener productos elaborados y/o preservados" (artículo 27).

Según el artículo 43 de la referida ley para poder desarrollar actividades pesqueras se requiere de un permiso de pesca, ya sea para operar embarcaciones de bandera nacional o de bandera extranjera, y de una licencia para operar plantas de procesamiento de productos pesqueros.

El artículo 11 del Reglamento de la Ley General de Pesca, aprobado por Decreto Supremo $\mathrm{N}^{\circ}$ 012-2001-PE, establece que el régimen de acceso a la actividad extractiva de recursos hidrobiológicos está constituido por las autorizaciones de incremento de flota y los permisos de pesca, los cuales se otorgan en función a las disposiciones reglamentarias $\mathrm{y}$ tomando en consideración el grado de explotación de los recursos.

En cuanto al régimen de acceso a la actividad de procesamiento, el Reglamento de la Ley General de Pesca refiere que está constituido por las autorizaciones de instalación y las licencias de operación de plantas de procesamiento.

Bajo dicho contexto, quien quiera realizar actividad extractiva debe previamente contar con un permiso de pesca, a excepción cuando esta actividad sea realizada con fines de consumo doméstico o trueque sin fines de lucro, es decir de subsistencia, y deportiva cuando no se emplee embarcaciones, conforme al artículo 29 del referido reglamento. Del mismo modo, cuando se requiera realizar actividades de procesamiento, contar con una licencia de operación.

Para poder realizar las referidas actividades no basta con tener los títulos habilitantes, sino también, luego de haberlo obtenido, cumplir con determinadas condiciones y exigencias, puesto que determinados incumplimientos acarrearán que se declare la caducidad del título habilitante y consecuentemente el administrado se verá imposibilitado de continuar realizando actividad extractiva o de procesamiento.

El presente artículo tiene como finalidad dar a conocer cómo se ha regulado la caducidad en el ámbito de la actividad pesquera, específicamente respecto a los permisos de pesca y licencias de operación de plantas de procesamiento.

En tal sentido, se desarrolla el modo en que está regulada la caducidad en la Ley General de Pesca y su Reglamento, y se detallan las causales por las cuales procede declararla.

\section{REGULACIÓN DE LA CADUCIDAD EN LA LEY GENERAL DE PESCA Y SU REGLAMENTO}

La regulación de la caducidad en materia de recursos naturales se encuentra en la Ley Orgánica para el aprovechamiento sostenible de los recursos naturales, Ley $\mathrm{N}^{\circ} 26821$, la cual establece en su artículo 30 que "la aplicación de las causales de caducidad se sujetará a los procedimientos que establezcan las leyes especiales (...). La caducidad determina la reversión al estado de la concesión”.

En lo que respecta a los recursos hidrobiológicos, la regulación de la caducidad en la Ley General de Pesca data del año 2008, tras la modificación de dicha ley a través del Decreto Legislativo $\mathrm{N}^{\circ}$ 1027.

No obstante, lo antes señalado, la caducidad fue regulada en el año 1994 en el Reglamento de la referida ley, aprobado por Decreto Supremo $\mathrm{N}^{\circ}$ 001-94-PE, y posteriormente también se reguló en el Reglamento, vigente a la fecha, aprobado por Decreto Supremo No 012-2001-PE, así como en el Reglamento de Ordenamiento de la Pesquería del Bacalao de Profundidad, aprobado mediante Resolución Ministerial $\mathrm{N}^{\circ}$ 236-2001-PE.

La regulación de la caducidad en la Ley General de Pesca se debió, según la Exposición de Motivos del Decreto Legislativo $N^{\circ} 1027$, a la necesidad de que su declaración sea efectuada siempre que exista un procedimiento administrativo en el que se haya otorgado al administrado la posibilidad de presentar los alegatos y los medios de prueba correspondientes. Según dicha exposición de motivos las disposiciones 
de plantas de procesamiento en la Ley General de Pesca y su Reglamento

Regulation of the expiration of the fishing permit and of the operating license

of processing plants in the general fisheries law and its regulations

pesqueras no estaban acorde al derecho a la defensa y debido proceso pues establecían una caducidad de pleno derecho. Sin embargo, se advierte que en el Reglamento de la referida ley se sigue haciendo referencia a que la caducidad opera de pleno derecho.

Adicionalmente se alegó en la exposición de motivos que era importante,

Proponer un Decreto Legislativo que esclarezca, sistematice y actualice disposiciones de la Ley General de Pesca relacionadas con el uso de los derechos administrativos (...) que aseguren que éstos se ejercen con sujeción a los intereses de la Nación y que en caso de incumplimiento de las condiciones de vigencia de los derechos otorgados o de las disposiciones legales correspondientes su reversión se efectúe de acuerdo con el debido procedimiento con el propósito de evitar arbitrariedades. (Primera página)

Del párrafo precedente se advierte que para la Administración era necesario contar con una norma con rango de ley que regule la caducidad en materia pesquera, lo cual es concordante con la Ley Orgánica para el aprovechamiento sostenible de los recursos naturales que dispone que la aplicación de las causales de caducidad se aplicará de acuerdo a las leyes especiales, de lo contrario la precisión de que exista un procedimiento en donde el administrado pueda presentar sus alegatos pudo haberse realizado en el reglamento.

El artículo 44 de la Ley General de Pesca regula a la caducidad como una consecuencia ante el ejercicio de los derechos administrativos otorgados sin observar o sin cumplir las especificaciones previstas en el derecho otorgado, así como las condiciones y disposiciones emitidas. Este artículo establece que la declaración de la caducidad debe realizarse previo procedimiento administrativo que asegure el derecho de defensa de los administrados y con estricta sujeción al debido procedimiento.

Tal como está redactado el referido artículo, aparentemente cualquier incumplimiento de las condiciones y especificaciones previstas en el título habilitante o en las disposiciones normativas correspondientes podría ameritar la declaración de la caducidad.
Al respecto, según Baca (2017) la doctrina se ha ocupado de destacar que la caducidad está vinculada a la omisión del cumplimiento de obligaciones esenciales y no de cualquier obligación.

La Ley General de Pesca no detalla los parámetros ni criterios para determinar qué tipo de incumplimiento amerita que se declare la caducidad, como por ejemplo si se trata de un incumplimiento grave. El establecimiento de los parámetros para determinar los supuestos específicos en los que procede su declaración pudo constituir la base que debió observar el Poder Ejecutivo al momento de reglamentarla, otorgando de esta manera reglas claras tanto para la Administración como para los administrados.

Asimismo, la Ley General de Pesca no especifica de manera expresa que tipo de procedimiento debe seguirse para declararla, un sancionador o no; no obstante, esta ley no establece que la caducidad sea una sanción, pues el artículo 78 establece como sanciones a la multa, suspensión de la autorización, permiso y licencia, el decomiso y la cancelación definitiva de la autorización, permiso o licencia, de lo que se desprende que no se desarrollaría un procedimiento administrativo sancionador.

Lo antes indicado permite concluir que la caducidad dentro del ámbito pesquero no constituye formalmente una sanción por cuanto de acuerdo al principio de legalidad, en materia sancionadora, establecido en la Ley del Procedimiento Administrativo General, esta debe estar catalogada como tal en una norma con rango de ley, lo cual no se evidencia en la Ley General de Pesca.

Sin perjuicio de que la Ley General de Pesca no catalogó a la caducidad como sanción, de la revisión de su reglamento se evidencia que esto no estaba claro para la Administración, pues se la menciona como una sanción y que será declarada por la ex Dirección General de Sanciones, actualmente Dirección de Sanciones de la Dirección General de Supervisión, Fiscalización y Sanción del Despacho Viceministerial de Pesca y Acuicultura del Ministerio de la producción, conforme se detallará más adelante.

A la fecha la declaración de la caducidad de los permisos de pesca y de las licencias de operación está asignada como función a la Dirección 
General de Pesca para Consumo Humano Directo e Indirecto, conforme se advierte en el Reglamento de Organización y Funciones del Ministerio de la Producción, con lo cual administrativamente se aparta del esquema general previsto para las sanciones catalogadas como tal en la Ley General de Pesca.

Al respecto, en la medida que se determine que esta debe ser considerada como una sanción de manera expresa, no bastará que se la mencione como tal a nivel de reglamento, por cuanto, como ya se expuso anteriormente, la determinación como tal debe ser efectuada en una norma con rango de ley.

Otro aspecto relevante sobre la caducidad en materia pesquera es que tanto la Ley General de Pesca como su Reglamento no establecen de manera expresa desde cuando opera, lo cual es importante esclarecer tanto para la Administración como para el administrado, toda vez que permitiría determinar si es que este incurrió o no en una infracción, considerando, por ejemplo, que constituye una infracción el realizar actividades pesqueras sin contar con el permiso de pesca.

Con relación a este aspecto, Baca (2017) refiere que entre la configuración de la causal de caducidad y la declaración de caducidad el título habilitante sigue siendo válido, para este autor, en los casos de incumplimiento el título será eficaz en tanto la Administración no declare la extinción y solo será ineficaz a partir de ese entonces.

Los supuestos por los cuales se declara y opera la caducidad del permiso de pesca y la licencia de operación que se encuentran regulados en el reglamento de la Ley General de Pesca son los siguientes:

\section{Causales de caducidad del permiso de pesca reguladas en el Reglamento de la Ley General de Pesca}

El permiso de pesca, conforme a la Ley General de Pesca y su Reglamento, habilita a realizar actividades extractivas y la consecuencia inmediata de la declaración de la caducidad es la imposibilidad de continuar extrayendo.

A continuación se detallan las causales previstas en el Reglamento de la Ley General de Pesca que ameritan la declaración de la caducidad.

\section{No presentar la certificación que pruebe la destrucción o desguace o la documentación que pruebe la exportación de las embarcaciones no siniestradas sustituidas.}

Esta causal está relacionada a la actividad extractiva de los recursos plenamente explotados, como es el caso de la anchoveta y la sardina, respecto de los cuales el Ministerio de la Producción no puede otorgar nuevos permisos de pesca a menos que se sustituya igual capacidad de bodega de la flota existente, en caso se trate de embarcaciones de menor y mayor escala que se utilicen para realizar actividades extractivas en el ámbito marino.

Esta causal de caducidad se encuentra prevista en el numeral 12.5 del artículo 12 del Reglamento de la Ley General de Pesca y está referida específicamente respecto a las embarcaciones no siniestradas. El referido numeral establece lo siguiente:

Los armadores de embarcaciones pesqueras no siniestradas, que sean materia de sustitución de igual capacidad de bodega, deberán acreditar ante el Ministerio de la Producción la certificación expresa que pruebe la destrucción o desguace, o la exportación de las embarcaciones no siniestradas sustituidas, emitida por la autoridad marítima o en caso de su exportación con la documentación correspondiente. (...) Será causal de caducidad del permiso de pesca otorgado, incumplir con presentar la mencionada certificación, o de ser el caso la documentación de exportación, en un plazo de cuarenta y cinco (45) días, contados a partir del día siguiente de la notificación de la resolución administrativa que otorga el permiso de pesca. (...). (el subrayado es nuestro)

Se infiere que la causal de caducidad será declarada respecto del nuevo permiso otorgado en virtud a la sustitución, pero ¿qué pasará con el anterior permiso si es que el administrado cumple con acreditar lo exigido por la Administración? El numeral citado no establece cual es la consecuencia.

Este numeral 12.5 fue introducido en el artículo 12 a través del Decreto Supremo $\mathrm{N}^{\circ}$ 004-2002-PRODUCE, a fin de evitar “(...) la pesca ilegal por parte de las embarcaciones 
de plantas de procesamiento en la Ley General de Pesca y su Reglamento

Regulation of the expiration of the fishing permit and of the operating license

of processing plants in the general fisheries law and its regulations

que han sido sustituidas y como consecuencia de ello, han perdido el permiso de pesca (...)", según la parte considerativa de dicho decreto.

Conforme al artículo 3 del Decreto Supremo $\mathrm{N}^{\circ}$ 015-2007-PRODUCE, están obligados a acreditar la destrucción, el desguace o la exportación aquellos:

Armadores que no hayan obtenido autorización de incremento de flota y permiso de pesca para operar dichas embarcaciones en la extracción de recursos hidrobiológicos y no hayan acreditado que son utilizadas para otros fines y que no son utilizada para otros fines y no realizarán actividades pesqueras.

De este numeral se desprende que para el caso en que las embarcaciones sigan estando aptas para su uso en la extracción de recursos hidrobiológicos pero que por diversos motivos no va a seguir extrayendo un recurso plenamente explotado procede su sustitución con otra embarcación debiendo demostrar que será usado ya sea en otra pesquería, exportado o que no realizará actividad pesquera.

Finalmente, corresponderá a la Administración evaluar si esta disposición es concordante con los principios establecidos en la Ley del Procedimiento Administrativo General que sirven de parámetros para la generación de disposiciones administrativas de carácter general, considerando que la verificación de la realización de actividades ilegales con las embarcaciones que han sido sustituidas bien puede advertirse a través de la actividad de fiscalización, lo cual ameritará la ejecución de acciones de interdicción al amparo del Decreto Legislativo $\mathrm{N}^{\circ}$ 1393, Decreto Legislativo que regula a la interdicción en las actividades ilegales en pesca.

\section{No solicitar la autorización de incremento de flota dentro del plazo establecido o haber obtenido dicha autorización antes del plazo en caso se produzca el siniestro con pérdida total de la embarcación}

Este supuesto se encuentra previsto en el artículo 18 del Reglamento de la Ley General de Pesca, el cual regula lo referente a las embarcaciones siniestradas con pérdida total.

Este artículo establece que para el caso de "embarcaciones siniestradas con pérdida total se solicita autorización de incremento de flota dentro de los tres años posteriores al siniestro", prorrogable por un año, "siempre que la solicitud sea formulada por el armador afectado para dedicarla a la pesquería originalmente autorizada."

El numeral 18.2 del artículo 18 dispone que "Vencido el plazo a que se refiere el párrafo anterior, el permiso de pesca caducará de pleno derecho sin que sea necesaria la notificación de parte del Ministerio (...)"

Se advierte que este numeral no precisa si opera la caducidad en caso no se solicite la autorización dentro del plazo. Bastaría que venza ese plazo para que opere, independientemente de si solicitó o no la autorización de incremento de flota.

Considerando las disposiciones que establece la Ley General de Pesca, así como también la Ley del Procedimiento Administrativo General la caducidad debe ser declarada previo procedimiento administrativo.

Asimismo, el numeral 18.3 establece "En caso de que la autorización de incremento de flota se otorgue antes del vencimiento del año a que se refiere el numeral 18.1, caducará automáticamente el permiso de pesca original de la embarcación."

Esta causal de caducidad no obedece a un incumplimiento, supuesto por el cual corresponde declarar la caducidad bajo los alcances del artículo 44 de la Ley General de Pesca, por lo que correspondería evaluar si esta figura es la adecuada para este supuesto.

Al respecto, Baca (2017) manifiesta que el dato esencial para la llamada caducidad - sanción, es el incumplimiento del titular.

De las disposiciones antes citadas se desprende que caducará el permiso de pesca en caso no se solicite la autorización de incremento de flota dentro del plazo previsto, y también en caso se otorgue el incremento antes del vencimiento del plazo de tres años antes indicado.

Al respecto, considerando que el permiso de pesca está ligado a la embarcación pesquera, si esta ya no puede ser utilizada es lógico que el permiso de pesca ya no pueda surtir efectos. 
Este artículo no establece qué es lo que pasa en caso la autorización de incremento de flota se otorgue después del vencimiento del plazo. Por ejemplo si es que el administrado solicitó el incremento de flota dentro del plazo antes referido pero por razones imputables a la administración se otorgó luego de vencido este.

Al respecto, independientemente de que se otorgue antes o después la autorización de incremento de flota, el permiso de pesca de la embarcación siniestrada con pérdida total debe quedar sin efecto.

\section{No demostrar la realización de actividades de pesca en dos años consecutivos y que se cuenta con las condiciones de operación establecidas}

De acuerdo a lo establecido en el numeral 33.8 del artículo 33 del Reglamento de la Ley General de Pesca, "los armadores que incumplan con demostrar que han realizado actividades de pesca y que cuentan con las condiciones de operación establecidas son sancionados con la caducidad del permiso de pesca (...)".

Esta causal no procede cuando el armador haya decidido por razones de carácter económico no realizar faenas de pesca en un periodo mayor a un año, lo cual debe ser comunicado a la Administración.

Tampoco procede esta causal en el caso en que por motivos de fuerza mayor no se logre demostrar que se ha cumplido con el esfuerzo pesquero mínimo anual, lo cual también requiere ser acreditado y puesto a conocimiento del Ministerio de la Producción.

En el numeral 33.8 se cataloga a la caducidad como una sanción, pues refiere que ante tal incumpliendo, “(...) los armadores serán sancionados con la caducidad del permiso de pesca de sus embarcaciones (...)". Esta precisión no se encuentra alineada a lo dispuesto en la Ley del Procedimiento Administrativo General, por cuanto no existe una norma con rango de ley que establezca que la caducidad es una sanción, como ya se ha indicado anteriormente.

\section{No acreditar no haber incrementado la capacidad de bodega autorizada}

Para mantener la vigencia del plazo y el contenido del permiso de pesca los armadores pesqueros deben acreditar que no se ha incrementado la capacidad de bodega autorizada, para lo cual deben presentar una declaración jurada en el mes de enero de cada año ante la Dirección General de Pesca para Consumo Humano Directo e Indirecto.

Conforme a lo dispuesto en el numeral $33.6 \mathrm{del}$ artículo 33 del Reglamento de la Ley General de Pesca, en la medida en que no se cumpla con tal acreditación la embarcación pesquera no será incluida en la lista de embarcaciones autorizadas a realizar actividades extractivas a que se refiere el artículo 14, quedando suspendido el permiso de pesca. Si es que la suspensión es por dos años consecutivos corresponde que se declare la caducidad del permiso de pesca.

En concreto, si el administrado no acredita la no modificación de la capacidad de bodega por dos años consecutivos corresponderá que se declare la caducidad de su permiso.

Cabe precisar que se encuentra tipificado como infracción, en el numeral 19 del artículo 134 del Reglamento de la Ley General de Pesca, el incrementar la capacidad de bodega de la embarcación sin contar con la autorización correspondiente, lo cual es sancionado con multa.

De lo antes señalado se desprende que además de la declaración de la caducidad por no acreditar que no se modificó la capacidad autorizada, al haberla modificado, se le aplicará una sanción de multa.

Esta causal de caducidad conforme al contenido del numeral 33.6 antes citado, no operaría para el caso de las embarcaciones artesanales, pues el listado a que se refiere el artículo 14 solo comprende a las embarcaciones de menor y mayor escala.

\section{No pagar los derechos de pesca}

De acuerdo a la Ley Orgánica para el aprovechamiento sostenible de los recursos naturales, todo aprovechamiento de estos recursos por parte de particulares da lugar a una retribución económica que se determina por criterios económicos, sociales y ambientales.

A esta retribución en materia pesquera se le denomina derechos de pesca y sirve para financiar "Los costos que el Estado efectúa para garantizar la conservación y aprovechamiento responsable de los recursos hidrobiológicos, 
de plantas de procesamiento en la Ley General de Pesca y su Reglamento

Regulation of the expiration of the fishing permit and of the operating license

of processing plants in the general fisheries law and its regulations

incluidos los costos de investigación, vigilancia, control y planeamiento del desarrollo de las pesquerías", conforme lo establece el artículo 3 del Reglamento de la Ley General de Pesca.

Están obligados a pagar los derechos de pesca los armadores de embarcaciones pesqueras mayores de 32, $6 \mathrm{~m} 3$ de capacidad de bodega, es decir embarcaciones de mayor escala y las embarcaciones de menor escala con las que se realice actividad extractiva en el ámbito marino, conforme se desprende del artículo 40 de dicho reglamento.

Cabe precisar que se encuentran exceptuados del pago por derecho de pesca quienes realicen actividades de investigación pesquera que implique la toma de muestra o especímenes sin valor comercial.

El incumplimiento del pago de los derechos de pesca de manera consecutiva o alternada en más de un semestre amerita que se declare la caducidad del permiso de pesca, según lo dispuesto en el artículo 43 del Reglamento de la Ley General de Pesca.

La subsanación del incumplimiento luego de iniciado el procedimiento para declarar la caducidad del permiso de pesca no impide que se continúe con el procedimiento de caducidad. Esto implica que la Administración presupone que el administrado continuará con este tipo de conductas.

\section{Causales de caducidad de las licencias de operación}

Para realizar actividades de procesamiento de recursos hidrobiológicos ya sea para consumo humano directo o indirecto se requiere de una licencia para la operación de la planta de procesamiento.

En la medida que se declare la caducidad, al igual que en el caso del permiso de pesca, el administrado no tendrá un título que le habilite continuar procesando.

El artículo 44 de la Ley General de Pesca establece lo siguiente:

Artículo 44.- Las concesiones, autorizaciones y permisos, son derechos específicos que el Ministerio de la Producción otorga a plazo determinado para el desarrollo de las actividades pesqueras, conforme a lo dispuesto en la presente Ley y en las condiciones que determina su Reglamento.

Corresponde al Ministerio de la Producción, verificar que los derechos administrativos otorgados se ejerzan en estricta observancia a las especificaciones previstas en el propio título otorgado así como de acuerdo con las condiciones y disposiciones legales emitidas, a fin de asegurar que éstos sean utilizados conforme al interés de la Nación, el bien común y dentro de los límites y principios establecidos en la presente ley, en las leyes especiales y en las normas reglamentarias sobre la materia.

En caso de incumplimiento, el Ministerio de la Producción, a través de los órganos técnicos correspondientes, dicta la resolución administrativa de caducidad del derecho otorgado que permita su reversión al Estado, previo inicio del respectivo procedimiento administrativo, que asegure el respeto al derecho de defensa de los administrados y con estricta sujeción al debido procedimiento.

De la revisión del artículo antes citado, que es el único en la Ley General de Pesca que hace alusión a la caducidad, se advierte que no hace referencia a la licencia.

Sin embargo, a través del Decreto Supremo $\mathrm{N}^{\circ}$ 015-2016-PRODUCE se incorporó el numeral 53.5 al artículo 53 del Reglamento de la Ley General de Pesca, que establece las causales de caducidad de la licencia de operación, antes de este decreto el Reglamento de la Ley General de Pesca no contemplaba la posibilidad de declarar la caducidad de la licencia.

Las causales por las que procede la declaración de la caducidad se detallan a continuación:

a) La suspensión de la licencia de operación, incluyendo la referida al incumplimiento de los compromisos ambientales, por más de dos (02) años consecutivos, contados desde la finalización del plazo otorgado para invertir en los compromisos ambientales o vencido el plazo que autoriza la suspensión por razones de carácter económico.

b) La inoperatividad, abandono, desmantelamiento o falta de equipos para la operación de la planta, lo cual se constata con la inspección o el seguimiento a la recepción o descarga 
de materia prima, de los dos (02) últimos años, proporcionada por las Empresas ejecutoras del "Programa de Vigilancia y Control de la Pesca y Desembarque en el Ámbito Marítimo", según el caso, salvo caso fortuito o fuerza mayor. No se consideran caso fortuito o fuerza mayor las circunstancias que se relacionen con acontecimientos previsibles, ordinarios, resistibles o inherentes a la propia dinámica de la actividad pesquera.

c) Cuando no se mantengan las condiciones exigidas legalmente para la emisión de la Licencia de Operación. (Artículo $53.5 \mathrm{del}$ Decreto Supremo N 015-2016-PRODUCE).

Al respecto, no se establece si opera esta causal cuando el no mantenimiento de las condiciones exigidas legalmente obedece a un incumplimiento por parte del administrado o a causa de una disposición normativa.

Esta causal es aparentemente similar a la causal de revocación prevista en el sub numeral 212.1.2 del numeral 212.1 del artículo 212 del Texto Único Ordenado de la Ley del Procedimiento Administrativo General, que señala "Cuando sobrevenga la desaparición de las condiciones exigidas legalmente para la emisión del acto administrativo cuya permanencia sea indispensable para la existencia de la relación jurídica creada."

Al respecto, Morón (2017) señala que las circunstancias cambiantes deben ser externas, exógenas y extrínsecas a la conducta del administrado.

Para determinar cuáles son las condiciones legalmente exigidas para la emisión de la licencia de operación, se revisó las licencias otorgadas por el Ministerio de la Producción, entre ellas la Resolución Directoral $\mathrm{N}^{\circ}$ 468-2017-PRODUCE/DGPCHDI en donde se advierte que para el otorgamiento de la misma se evalúa el cumplimiento de los requisitos previstos en el Texto Único de Procedimientos Administrativos del Ministerio de la Producción: solicitud con carácter de declaración jurada, pago por derecho de trámite y contar con protocolo sanitario expedido por el Organismo Nacional de Sanidad Pesquera (SANIPES).
En cuanto al primer requisito en la referida resolución se señala que se ha cumplido con precisar el número de la resolución que autorizó la instalación de la planta y que se cuenta con la constancia de verificación de implementación del instrumento de gestión ambiental y de capacidades instaladas. Asimismo, se señala en la resolución que la administrada ha cumplido con implementar los compromisos ambientales.

De lo antes indicado, se desprende que las condiciones que debería mantener el administrado es contar con el protocolo sanitario o con la implementación del instrumento de gestión ambiental.

Además de las causales antes indicadas, existen otros incumplimientos que han sido determinados por la Administración que podrían ameritar la declaración de la caducidad, lo cuales no son descritos de manera clara.

De la revisión de la Resolución Directoral $\mathrm{N}^{\circ}$ 468-2017-PRODUCE/DGPCHDI se advierte que su artículo 3 contempla ciertas condiciones que debe cumplir la empresa titular de la licencia. Estas se encuentran detalladas en el numeral 53.1 del artículo 53 del Reglamento de la Ley General de Pesca y son las siguientes:

a) Contar con sistemas de producción que aseguren el adecuado aprovechamiento de los recursos pesqueros;

b) Contar con los medios adecuados de transporte y de recepción que eviten mermas y permitan la óptima conservación de la materia prima;

c) Reducir y minimizar los riesgos de la contaminación ambiental implementando sistemas de recuperación y tratamiento de residuos y desechos, sin perjuicio de lo establecido en los artículo 78, 79 y $80 \mathrm{del}$ Reglamento de la Ley General de Pesca;

d)Cumplir las normas del Reglamento de Seguridad e Higiene Industrial;

e) Cumplir las disposiciones que dicte la autoridad sanitaria competente; y

f) Implementar sistemas de aseguramiento de la calidad. (Artículo 3 de la Resolución Directorial $\mathrm{N}^{\circ}$ 468-2017-PRODUCE/ DGPCHDI). 
de plantas de procesamiento en la Ley General de Pesca y su Reglamento

Regulation of the expiration of the fishing permit and of the operating license

of processing plants in the general fisheries law and its regulations

El artículo 4 de la referida resolución señala que el incumplimiento de lo establecido en el artículo 3 será causal de caducidad del derecho otorgado o de la aplicación de las sanciones que pudieran corresponder, sin perjuicio de la aplicación del artículo 53.5 del artículo 53 del Reglamento de la Ley General de Pesca.

Lo que se estaría realizando a través del artículo 4 de la Resolución Directoral $\mathrm{N}^{\circ}$ 468-2017-PRODUCE/DGPCHDI es la creación de una nueva causal de caducidad y tal como está redactado generaría en cualquier administrado una incertidumbre pues estará sujeto a lo que interprete la Administración.

Al respecto, se considera necesario que las causales de caducidad sean expresamente establecidas como mínimo en una norma de carácter reglamentaria, a fin de otorgar mayor seguridad jurídica a los administrados.

\section{CONCLUSIONES}

La caducidad en la Ley General de Pesca se encuentra prevista para los casos en que el administrado incumpla las condiciones previstas en el título habilitante, así como en las disposiciones normativas. Esta ley no regula de a la caducidad como una sanción administrativa.

Las causales previstas en el Reglamento de la Ley General de Pesca, aprobado por Decreto Supremo N 012-2001-PE, no necesariamente obedecen a un incumplimiento de las disposiciones pues en algunos casos opera simplemente ante la necesidad de especificar que el permiso otorgado ya no sufrirá efectos, considerando que la embarcación no será utilizada ya sea porque fue siniestrada con pérdida total o porque el administrado decide no seguir explotando el recurso que fue autorizado con el permiso de pesca.

A efectos de otorgar mayor seguridad jurídica a los administrados las causales de caducidad deben estar previamente establecidas en las disposiciones normativas y se debe evitar crearlas mediante actos administrativos.

Resulta necesaria la revisión por parte de la Administración de la concordancia de las causales de caducidad con los principios previstos en la Ley del Procedimiento Administrativo General, así como el marco general previsto en la Ley General de Pesca.

\section{FUENTES DE INFORMACIÓN}

\section{Fuentes bibliográficas}

Huergo, Alejandro (2007). Las sanciones administrativas. Madrid, España: Iustel

Morón, Juan (2017). Comentarios a la Ley del Procedimiento Administrativo General. Lima, Perú: Gaceta Jurídica.

\section{Fuentes electrónicas}

Baca, Víctor (2017). La Naturaleza revocatoria y los Límites de la Extinción de los Títulos Habilitantes por incumplimiento de Condiciones. Madrid, España. Editorial Reus. Recuperado de https://books.google. com.pe/books?id $=7$ rxUDwAAQBAJ\&pg $=$ P A 886\&lpg $=$ PA $886 \&$ dq $=$ diferencias + entre + la + sanci\% $\% 3 \% B 3 n+y+l a+$ caducidad $+d e+u$ $\mathrm{n}+$ titulo + habiliante \& source $=$ bl\&ots $=\mathrm{KrT1}$ P PCOUE\&sig $=$ syVJfirOolcQBIDTs5WrOLH p $8 W c \& h l=e s \& s a=X \& v e d=2 a h U K E w j A 2 M$ DOxObfAhVvx1kKHe99ADMQ6AEwC3o ECAYQAQ $\# \mathrm{v}=$ onepage $\& \mathrm{q}=$ diferencias $\% 20$ entre $\% 201 \mathrm{a} \% 20$ sanci $\%$ C3\%B3n $\% 20 \mathrm{y} \% 20$ la $\% 20$ caducidad $\% 20$ de $\% 20$ un $\% 20$ titulo $\% 20$ habiliante $\& \mathrm{f}=$ false

Flores, Juan (2017). La caducidad de los actos administrativos. Recuperado de https://scielo.conicyt.cl/scielo.php?script= sci_abstract\&pid=S0718-095020170 $002 \overline{0} 0010 \& \operatorname{lng}=$ pt\&nrm=iso

Morón, Juan. (2011). La revocación de actos administrativos, interés público y seguridad jurídica. Recuperado de http://revistas. pucp.edu.pe/index.php/derechopucp/article/ view/3002/3547

Ponce, Carlos (2014). La declaración de caducidad de los derechos de aprovechamiento de recursos naturales renovables en el Perú y su problemática. Recuperado de http:// revistas.uap.edu.pe/ojs/index.php/LEX/article/ view/42/864

Presidencia del Consejo de Ministros (2008) Exposición de Motivos del Decreto Legislativo $\mathrm{N}^{\circ}$ 1027, Decreto Legislativo que modifica la Ley General de Pesca - Decreto Ley $\mathrm{N}^{\circ}$ 25977. Recuperado de: http://spij.minjus.gob. pe/Textos-PDF/Exposicion_de_Motivos/DL2008/DL-1027.pdf. 


\section{Fuentes normativas}

Congreso de la República (1997). Ley $\mathrm{N}^{\circ}$ 26821, Ley Orgánica para el aprovechamiento sostenible de los recursos naturales. En Diario oficial El Peruano. Lima, Perú.

Ministerio de la Producción (2017). Resolución Directoral $\quad \mathrm{N}^{\circ}$ 468-2017-PRODUCE/ DGPCHDI.

Presidencia de la República (1992). Decreto Ley $\mathrm{N}^{\circ}$ 25977, Ley General de Pesca. En Diario oficial El Peruano. Lima, Perú.

Presidencia de la República (2001). Decreto Supremo $\mathrm{N}^{\circ}$ 012-2001-PE, Aprueban el Reglamento de la Ley General de Pesca. En Diario oficial El Peruano. Lima, Perú.

Presidencia de la República (2002). Decreto Supremo N$^{\circ}$ 004-2002-PRODUCE, Modifican el Reglamento de la Ley General de Pesca y los DD.SS. N's. 004 y 008-2002-PE y 003-98PE. En Diario oficial El Peruano. Lima, Perú.

Presidencia de la República (2007). Decreto Supremo $\quad \mathrm{N}^{\circ}$ 015-2007-PRODUCE, Modificación del Reglamento de la Ley General de Pesca, aprobado por el Decreto Supremo $\mathrm{N}^{\circ}$ 012-2001-PE. (22 de agosto de 2007). En Diario oficial El Peruano. Lima, Perú.
Presidencia de la República (2008). Decreto Legislativo $\mathrm{N}^{\circ} 1027$, Decreto Legislativo que modifica la Ley General de Pesca. En Diario oficial El Peruano. Lima, Perú.

Presidencia de la República (2008). Decreto Ley No 25977. En Diario oficial El Peruano. Lima, Perú.

Presidencia de la Republica (2016). Decreto Supremo $\quad \mathrm{N}^{\circ}$ 015-2016-PRODUCE, Establece disposiciones sobre la actividad de procesamiento pesquero para la producción de concentrados proteicos. (22 de julio de 2016). En Diario oficial El Peruano. Lima, Perú.

Presidencia de la República (2018). Decreto Legislativo $\mathrm{N}^{\circ}$ 1393, Decreto Legislativo que regula a la interdicción en las actividades ilegales en pesca. En Diario oficial El Peruano. Lima, Perú.

Presidencia de la República (2019). Decreto Supremo No 004-2019-JUS, Decreto Supremo que aprueba el Texto Único Ordenado de la Ley No 27444 - Ley del Procedimiento Administrativo General. (22 de enero de 2019). En Diario oficial El Peruano. Lima, Perú. 